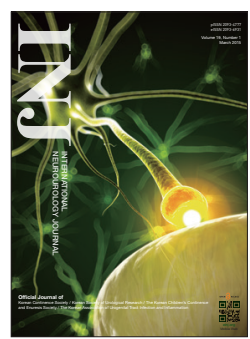

\title{
The Rise of On-Demand Research and Specific Applications: Optogenetics in Urology
}

\author{
Khae Hawn Kim \\ Associate Editor \\ Department of Urology, Gachon University Gil Medical Center, Incheon, Korea \\ E-mail:kimcho99@gilhospital.com
}

Optogenetics is a promising new field of research being applied in the treatment of various neurologic diseases. It has inspired many useful discoveries about sensory and motor neural circuits, enhancing our understanding of the underlying mechanisms of these diseases. However, studies of micturition centers and the central-peripheral neural circuits that control lower urinary tract are lacking. Therefore, the development of animal models using optogenetics-to investigate and map the central neural circuits associated with voiding-are needed, in order to advance optogenetics in neurourology. Moreover, such studies will be crucial in identifying the target neural cells activated and inhibited by optic stimulation in the brain centers.

In particular, inhibition of the neural hyperactivity in the micturition centers regulated by optogenetic application is a new therapeutic approach used to treat irreversible neurogenic bladder dysfunction. As a result, it is the first step in developing an optic treatment of bladder failure [1].

The review by Lee et al. [2] in this issue is the first to introduce the optogenetic method for treating lower urinary tract dysfunction. The attempt to apply optogenetics to diagnose and treat voiding dysfunction is a valuable step in expanding the urologic field of research. However, there are several obstacles to overcome, e.g., developing specific therapeutic targets using optogenetics in real-world applications.

The urothelium is controlled by neurotransmitters, releases chemical mediators, and responds to external stimuli by expressing sensory molecules. Jung et al. [3] suggest that aquaporin (AQP) 1 and caveolin (CAV) 1 might be closely related to bladder signaling activity and may play a specific role in bladder dysfunction. This article proposes potential roles of AQP1 and CAV1 in the urinary bladder.

Phosphodiesterase (PDE)-5 inhibitors are widely prescribed for the treatment of erectile dysfunction. Researchers have attempted to identify additional related clinical applications for the PDE-5 inhibitors. Of these, mirodenafil is the most recently developed PDE-5 inhibitor and has proven clinical efficacy in the treatment of ED. The article by Choi et al. [4] in this issue suggests that mirodenafil may be useful in the clinical treatment of bladder dysfunction caused by chronic bladder ischemia.

The autonomic nervous system has a prominent influence on both the filling and voiding phases of micturition. Release of acetylcholine (ACh) that binds nicotinic ACh receptors to the postsynaptic neurons has been known to play an important role on urinary bladder function. Kim et al. [5] briefly review in this issue recent findings on the nicotinic ACh receptors' control of urinary bladder detrusor overactivity in a rat model.

Depression and sexual dysfunction both involve serotonin signal pathways. In particular, the reduction in stress and serotonin regulation by physical activity might suggest a possible avenue to help prevent and treat depression that can be caused by sexual dysfunction. Kim et al. [6] in this issue focuses mainly on identifying the effect of treadmill exercise on emotional depression induced by stress, focusing on the expression of 5-hydroxytryptamine $1 \mathrm{~A}\left(5-\mathrm{HT}_{1 \mathrm{~A}}\right)$ receptors in the dorsal raphe nucleus as detected by immunohistochemical and western blot methods. Depressive symptomology considered in this study 


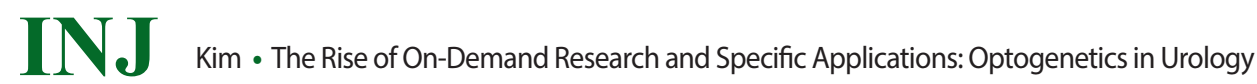

was usually associated with sexual dysfunction. Theanti-depressive effect of physical exercise may improve such symptomology via 5-HT signaling. We anticipate recognition of the role of 5-HT-both its regulation and its antidepressant effects-associated with physical activity as being useful in ameliorating sexual disorders.

Research of these study topics is often undertaken in an ondemand manner by a number of scientists in a variety of fields.

I am skeptical about the potential for making the needed advances in most such topics, as there are three main obstacles. First, because the goal of on-demand research, generally, is to keep research expenses as low as possible, such research entails insufficient resources for training, managing, and motivating the research workforce. Second, continuity and durability problems increase for on-demand research as the projects increase in size. Finally, clinical applicability is a third issue.

- Conflict of Interest: No potential conflict of interest relevant to this article is reported.

\section{REFERENCES}

1. Kim KH, Kim YH. Bladder failure? Int Neurourol J 2012;16:20910.

2. Lee KW, Kim D, Yoo S, Lee H, Lee GH, Nam Y. Emerging neural stimulation technologies for bladder dysfunctions. Int Neurourol J 2015;19:3-11.

3. Jung S, Kim SO, Cho KA, Song SH, Kang TW, Park K, et al. Loss of caveolin 1 is associated with the expression of aquaporin 1 and bladder dysfunction in mice. Int Neurourol J 2015;19:34-8.

4. Choi H, Bae JH, Shim JS, Park JY, Moon DG, Lee JG. Mirodenafil prevents bladder dysfunction induced by chronic bladder ischemia in rats. Int Neurourol J 2015;19:19-26.

5. Kim HS, Park WJ, Park EY, Koh JS, Hwang TK, Kim JC. Role of nicotinic acetylcholine receptor $\alpha 3$ and $\alpha 7$ subunits in detrusor overactivity induced by partial bladder outlet obstruction in rats. Int Neurourol J 2015;19:12-8.

6. Kim TW, Lim BV, Baek D, Seo JH. Stress-induced depression is alleviated by aerobic exercise through up-regulation of 5-hydroxytryptamine 1A receptors in rats. Int Neurourol J 2015;19:27-33. 